\title{
Greshner, Connie. (2020). Borderline Shine: A Memoir. Toronto: Dundurn Press.
}

\author{
Reviewed by Sarah Piers, MacEwan University
}

"Borderline Shine" by Connie Greshner is a memoir that describes a journey of finding a home, peace, and purpose while battling the devasting trauma caused by intergenerational violence. When Greshner was eight years old, her mother was brutally murdered by her father, which ignited her lifelong battle with depression and low self-esteem. Greshner details how the trauma she faces as a young girl affects her relationship with herself, family, and friends. Greshner's book is divided into two parts. The first part of the book outlines Greshner's struggles in childhood, adolescence, and early adulthood. The second part of the book details Greshner's path to recovery through accountability, awareness, and acceptance. Ultimately, Greshner is able to break the vicious cycle of intergenerational violence and find a home with love, purpose, and stability. Although this book covers a lot of material, Greshner consistently talks about nature, reading, and time as a way to describe her journey of self-discovery and healing.

Greshner mentions a lot of ways she tries to escape her harsh reality. She talks about using drugs, alcohol, and sex as coping mechanisms to deal with her trauma. Greshner explains that these coping mechanisms only contributed to the cycle of intergenerational violence and were extremely ineffective. However, Greshner also uses nature as a coping mechanism to deal with her trauma. Nature is different in the respect that it is the only coping mechanism that demonstrates Greshner's 
growth and supports her journey of self-discovery. As a child, Greshner uses nature as an escape from her reality. After Greshner's mom died, and her dad was put in jail, she was placed in the care of an Aunt and Uncle who she did not know. During this time, Greshner felt very alone and "retreated to the forest" (p. 23) as often as she could. The use of nature as an escape occurs repeatedly throughout Greshner's time at boarding school. Greshner explains that she feels like she is "stuck inside four walls" (p. 29), and the only thing getting her through her misery is an "imaginary playground where [she] pretends to be free in the forest" (p. 29). As Greshner gets older, she describes nature as a place where she feels safe to express her emotions. In times of intense pain, Greshner would "release [her] sadness into the sea" (p. 57). The use of nature as a place to release emotions instead of escape emotions demonstrates the tremendous growth of Greshner's character. It shows that Greshner is starting to release some of her pain instead of trying to mask it. Towards the end of the book, Greshner describes nature as a place that "purifies [her]" (p. 210) and "reenergizes [her] body and soul" (p. 210). Nature is no longer used as an escape or a place to release emotion; instead, it is a place where she can feel "alive and powerful" (p. 187). The way Greshner describes nature coincides with place she is at in her journey of recovery. Greshner uses nature as an escape when she is unable to process her emotions. However, when Greshner starts to identify signs of trauma, she uses nature as a safe place to release her feelings. Once Greshner has found her purpose in life, she uses nature as a way to remind her how powerful, brave, and full of life she is. The way Greshner depicts nature is a unique; yet, powerful way to describe her path of recovery.

Another way Greshner describes her journey of self-discovery and healing is through reading. 
Greshner realizes at a young age that she has a passion for reading. After discovering "Lord of the Rings," Greshner becomes fascinated by the realm of fantasy and starts to imagine she is living in "Tolkien's world" (p. 29). Greshner uses "Lord of the Rings" as a way of escaping the realities of her trauma. At this stage, Greshner is not ready to work through her emotions. As Greshner enters the world of adolescence, she moves away from fantasy and reads books with characters that she can identify with. After reading "The Outsiders," Greshner concludes that she is living "in the world of Ponyboy Curtis and Dallas Winston" (p. 30). Greshner identifies with these characters as she also feels shame over who her family is. Greshner acknowledges that she cannot escape her past, and the rebellious personas of the characters become appealing to her. At this point in the book, Greshner starts to rebel against everything around her as a way to deal with her trauma, which coincides with the characters in the novel. Ultimately, Greshner's passion for reading greatly benefits her university education. Through her dedication to reading her university textbooks and taking diligent notes, Greshner achieves a 4.0 GPA and qualifies to receive scholarships that help her continue her education. Reading plays an immense role in Greshner's recovery. She is able to identify with characters that are similar to her, which helps her cope with her trauma. Further, Greshner is able to receive an excellent education, which leads to her discovering her purpose in life.

Greshner also talks about time as a way to describe the cycle of intergenerational violence and her path of healing. Throughout the novel, Greshner describes scenarios where "time bent." In other words, Greshner explains how it feels like time is stuck because she is experiencing the same signs of intergenerational violence over and over again. As a young child, Greshner witnesses 
domestic violence between her older brother and his girlfriend, just as she witnessed violence between her parents. Even as a young child, Greshner could see the "time bend" (p. 39) and cycle repeat itself. Greshner also remembers a time where she was consoling her young nephew because his parents were fighting. This is eerily similar to how Greshner and her siblings would comfort each other when their parents were arguing. In the first half of the novel, Greshner cannot escape this bending time. She is "emotionally stuck in her childhood" (p. 156) and cannot seem to break free. It is not until Greshner vows to break the cycle of violence with her children that she moves forward in time. After Greshner promises that she will fiercely protect her children, she feels as if both "time and space bent" (p. 214) and that she is "in another world" (p. 214). Greshner has finally broken free from the trauma caused by intergenerational violence. The way Greshner talks about time throughout the book reflects her journey of self-discovery and healing.

"Borderline Shine" is a raw, beautiful, and compelling book that unveils the trauma caused by intergenerational violence. Greshner reveals that the journey of acceptance, accountability, and awareness is extremely challenging, but with the proper supports in place, it is possible. It also brings attention to the different signs of trauma and how difficult it is to break the cycle of violence. This book is compelling, emotional, and heartfelt; therefore, I do not have any suggestions for improvement. However, I would be interested in reading about how Greshner's trauma has affected her current work as a mental health therapist. Although Greshner does not state an intended readership of her book, I would recommend it to sociologists, psychologists, anthropologists, or anyone interested in looking at how intergenerational trauma affects someone in every aspect of their life. It would also be beneficial to anyone who is interested in learning about the therapeutic effects of nature, reading, counselling, and relationships. 